\title{
Epigenetic Regulation of Cytokine Production in Human Amnion and Villous Placenta
}

\author{
Murray D. Mitchell, ${ }^{1}$ Anna P. Ponnampalam, ${ }^{2}$ and Gregory E. Rice ${ }^{1}$ \\ ${ }^{1}$ The University of Queensland Centre for Clinical Research, Royal Brisbane Hospital, Building 71/918, Herston, \\ QLD 4029, Australia \\ ${ }^{2}$ The Liggins Institute, University of Auckland, 2-6 Park Avenue, Private Bag 92019, Auckland 1023, New Zealand \\ Correspondence should be addressed to Murray D. Mitchell, murray.mitchell@uq.edu.au
}

Received 13 January 2012; Accepted 11 March 2012

Academic Editor: Felipe Vadillo-Ortega

Copyright (๑) 2012 Murray D. Mitchell et al. This is an open access article distributed under the Creative Commons Attribution License, which permits unrestricted use, distribution, and reproduction in any medium, provided the original work is properly cited.

\begin{abstract}
The mechanisms of human preterm labour appear inextricably linked to cytokine biosynthesis by gestational tissues. In turn, cytokine production by gestational tissues has been shown to be regulated by epigenetic mechanisms. In this paper, we demonstrate that cytokine production in gestational tissues is regulated epigenetically in a tissue-specific manner. Furthermore, we show that treatment with a histone deacetylation inhibitor can partially abrogate LPS-stimulated TNF $\alpha$ production in villous placenta but not amnion. LPS treatment significantly $(P<0.05)$ increased the production of IL- $1 \beta(\sim 10-34$-fold $)$, TNF $\alpha(\sim 23->100$-fold $)$ and IL10 ( 6-10-fold) after $24 \mathrm{~h}$ of treatment in villous explants, as expected. There were no significant LPS effects on IL1Ra production. AZA treatment did not have any significant effect on any cytokines' production tested either alone or in combination with LPS. Interestingly, however, the stimulatory effects of LPS on TNF $\alpha$ production were partially mitigated $(P<0.05)$ by TSA treatment in villous explants. We suggest caution in the consideration of histone deacetylation inhibitors in pregnancy due to the different responses in gestational tissues.
\end{abstract}

\section{Introduction}

Preterm birth is the leading cause of neonatal death worldwide with one million deaths directly resulting from premature birth. More children under the age of 5 years die due to preterm birth than to AIDS, malaria, or tuberculosis [1]. The rate of preterm birth in Australia is gradually increasing [2]. Recently, the importance of epigenetics as a regulator of gene expression has become apparent and, potentially, epigenetic differences are driving gene expression leading to preterm birth.

Epigenetics is the process by which interactions between genes and environment lead to stable changes in phenotype [3]. Epigenetic changes (e.g., DNA methylation, covalent histone modifications, etc.) are by definition heritable, meaning that effects brought about by the environment at critical periods of development (such as gestation) can have longterm detrimental consequences [4]. Indeed, certain epigenetic changes are passed between generations which might explain some of the familial and intergenerational effects observed for preterm birth [5]. Importantly and in contrast to genetic inheritance, epigenetic heritability is potentially reversible [6]. An epigenomics approach, thus, opens new avenues for therapeutic interventions.

Epigenetic information is conveyed via a synergistic interaction between mitotically heritable patterns of DNA methylation and histone-mediated modifications to the chromatin structure [7]. In mammals, DNA methylation primarily involves the addition of methyl groups to cytosine residues present in a $\mathrm{CpG}$ dinucleotide. Hypermethylation of promoter regions of genes is typically associated with transcriptional repression whereas hypomethylation is usually permissive for gene activity. Histone modifications consist of a plethora of enzymatic modifications including acetylation, methylation, ubiquitination, and phosphorylation of different amino acids in the $\mathrm{N}$ terminal tails of histone proteins, the combination of which is thought to determine the local conformational state of the chromatin. Currently, over 60 different histone modifications have been identified although actual numbers are likely to be significantly higher 


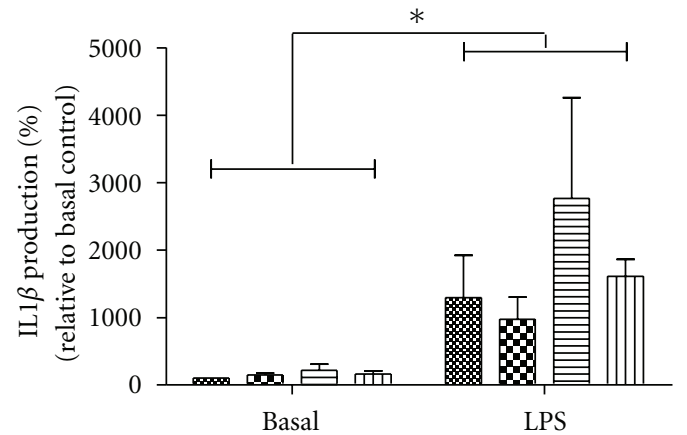

(a)

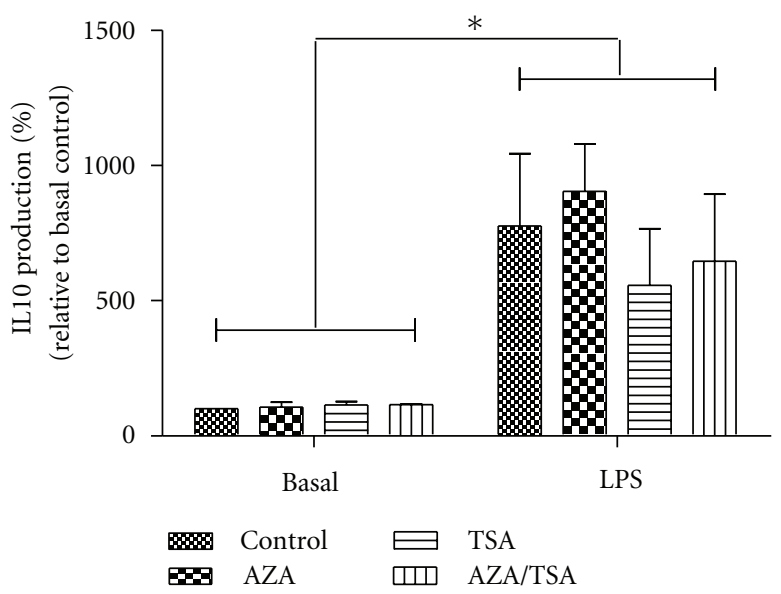

(c)

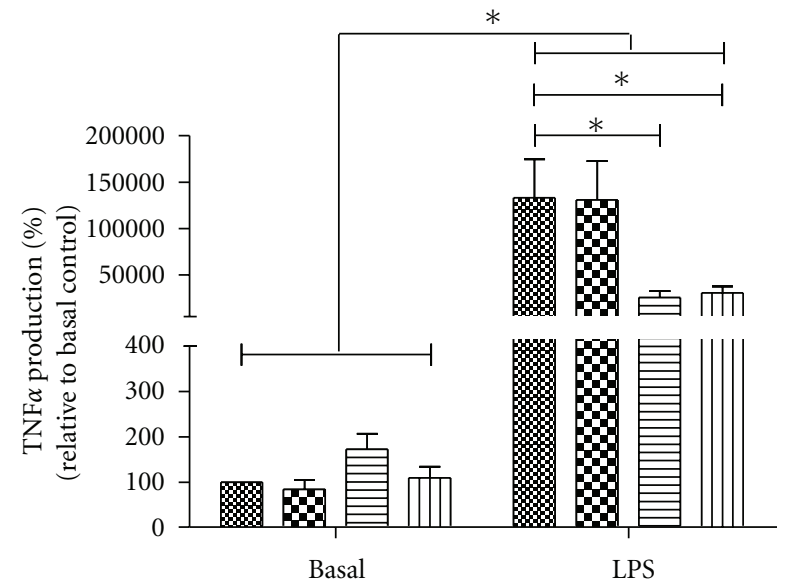

(b)

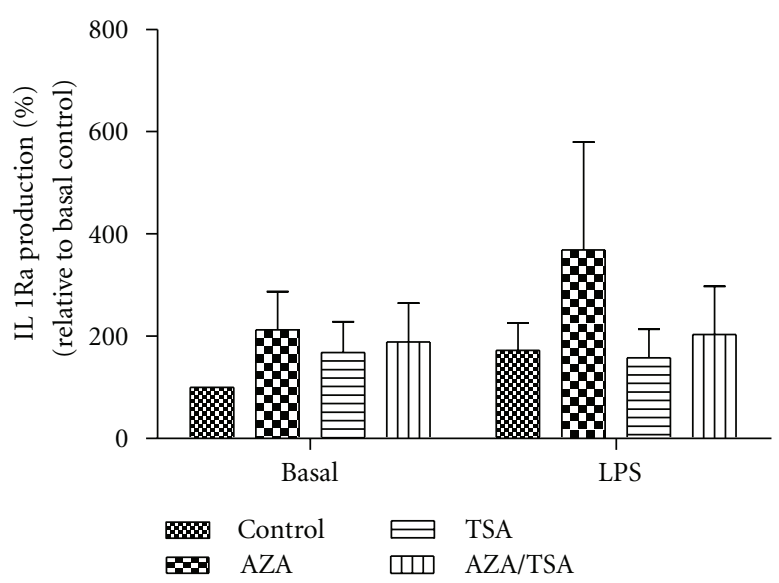

(d)

FIGURE 1: Effect of AZA and TSA on cytokine production by villous explants in the presence or absence of LPS. The levels of cytokines were measured by ELISA. The $y$-axis shows the rate of mean IL1 $\beta$ (a), TNF $\alpha$ (b), IL10 (c), and IL1Ra (d) production (as \% basal control values), normalized against the wet tissue weight, and the $x$-axis shows the different treatment groups. Error bars represent 1 S.E.M. ${ }^{*} P<0.05$, $n=3$.

[8]. Histone modifications are generally considered a less stable epigenetic mark than DNA methylation. Recent work has clearly demonstrated that epigenetic marks determine time- (temporal) and tissue-specific (spatial) aspects of gene expression throughout development. In contrast, others might carry an epigenetic signature that is less sensitive to the normal stimuli of labour, therefore, leading to dysfunctional labour or postdates delivery. The environment presumably plays a crucial role in bringing about these epigenetic changes that are critical for the safe passage of gestation and later outcomes. An increasing number of diverse factors are now known to epigenetically regulate genes, including age [9], inflammation [10], gender [11], genotype [12], stress [13], nutrition [14], metabolism [15], drugs [16], and infection [17], thus heightening the relevance of the study of the epigenetics of preterm birth.

Both classes of epigenetic modification (e.g., DNA methylation and covalent histone modifications) can be reversed through treatment with a chemical inhibitor: $2^{\prime}$-deoxy-5-azacytidine (AZA) that inhibits DNA methylation leading to global hypomethylation of DNA, while treatment with an inhibitor of histone deacetylation such as trichostatin A (TSA) leads to increased levels of histone acetylation. In both cases, intervention favours the transcriptionally active epigenetic state.

We demonstrated in an earlier study [16] that the combination treatment of human choriodecidual explants with AZA and TSA leads to a massive increase in IL- $1 \beta$ production in response to LPS. In the present study, we extend those findings to amnion and villous placenta.

\section{Materials and Methods}

2.1. Reagents. Lipopolysaccharide (LPS), 5-aza-2'-deoxycytidine (AZA), and trichostatin A (TSA) were purchased from Sigma Chemical (St. Louis, MO). Culture media and fetal calf serum (FBS) were from Life Technologies (Carlsbad, CA, USA). Human IL1 $\beta, T N F \alpha$, IL10, and IL1Ra ELISA kits were purchased from BD Bio Sciences. 


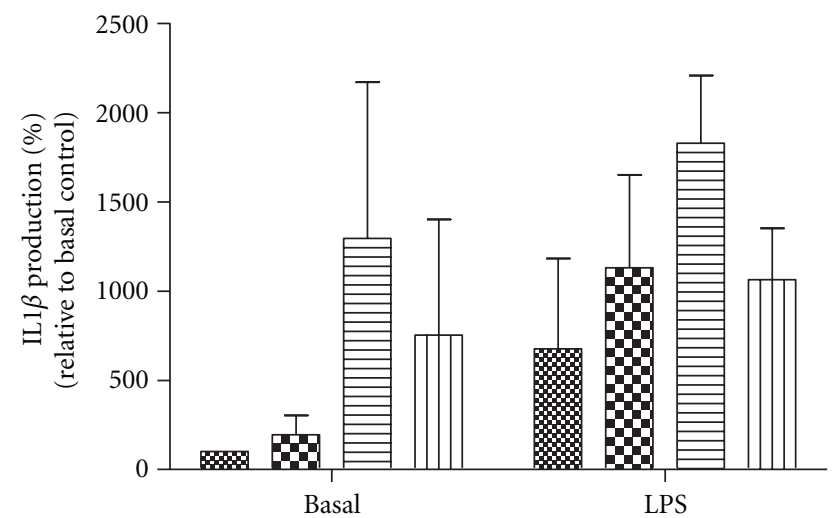

(a)

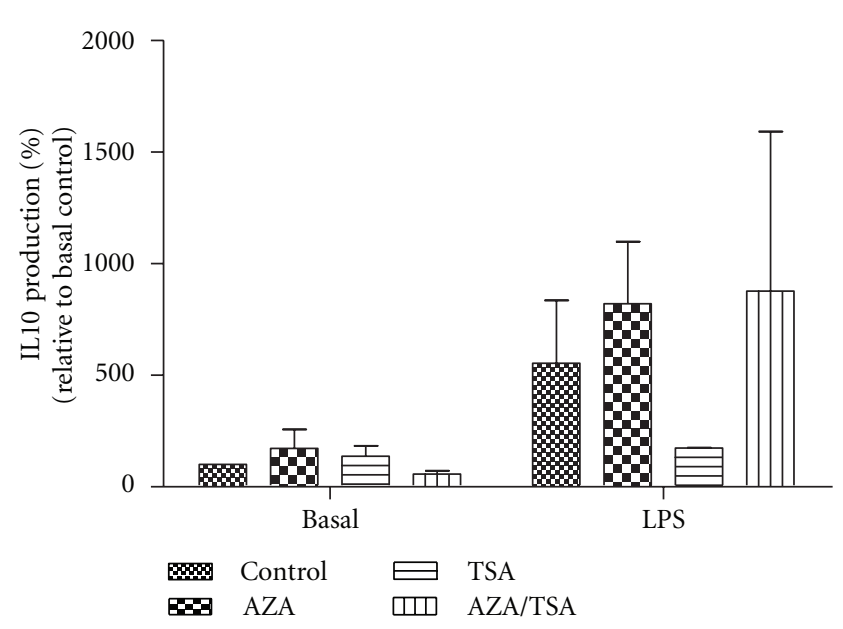

(c)

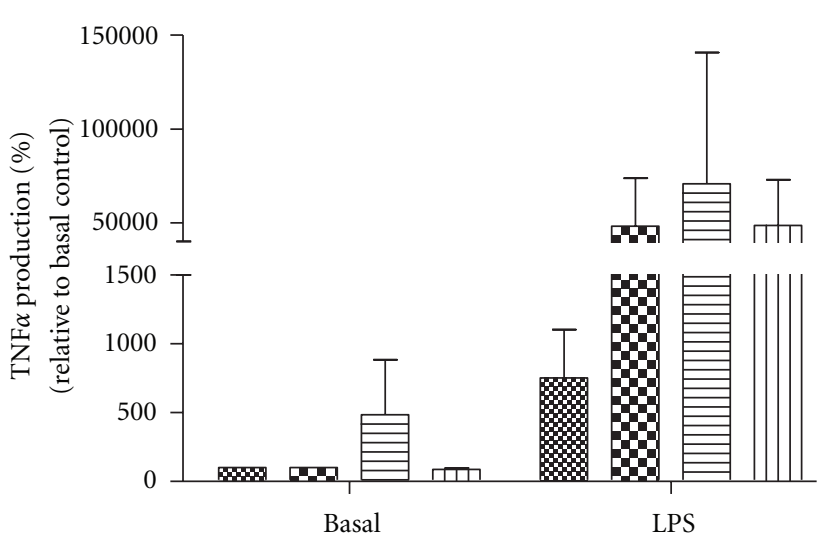

(b)

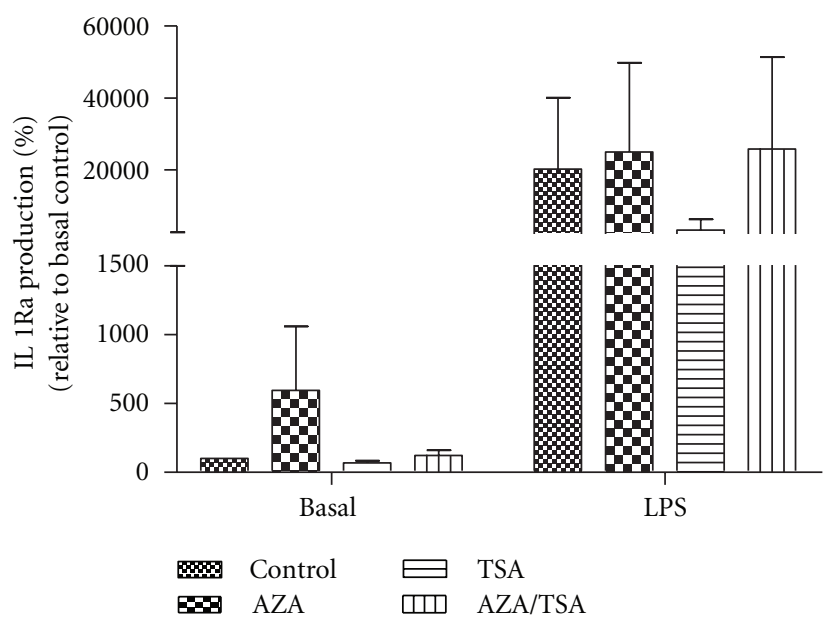

(d)

FIGURE 2: Effect of AZA and TSA on cytokine production by amnion explants in the presence or absence of LPS. The levels of cytokines were measured by ELISA. The $y$-axis shows the rate of mean IL1 $\beta$ (a), TNF $\alpha$ (b), IL10 (c), and IL1Ra (d) production (as \% basal control values), normalized against the wet tissue weight, and the $x$-axis shows the different treatment groups. Error bars represent 1 S.E.M.

2.2. Explant Cultures. Placental tissues were collected from women undergoing elective caesarean section at term, with the approval of the NorthernX Regional Ethics Committee. Three individual placentae from singleton pregnancies of healthy nonsmoking mothers were used in the study. In triplicate, villous and amnion tissues explants were cultured in 12-well plates (three pieces of tissue to a well) in DMEM/F12 media supplemented with glutamax, 10\% FBS, and $1 \%$ Antibiotic-antimycotic and incubated at $37^{\circ} \mathrm{C}$ in humid $5 \% \mathrm{CO}_{2} / 95 \%$ air for $24 \mathrm{~h}$ (modified from $[18,19]$ ).

Explant treatments included the use of 5-aza-2' -deoxycytidine (AZA), which inhibits DNA methylation, and/or Trichostatin A (TSA) which inhibits histone deacetylation. Doses and times were chosen to be consistent with published literature $[18,20] .24$ hours following placental dissection, the media were replaced with serum-free media (DMEM/F12 with glutamax and $0.1 \%$ Bovine gamma globulin and $1 \%$ Antibiotic-antimycotic medium). Explants were treated with either $200 \mathrm{nM}$ AZA alone, TSA $(300 \mathrm{nM})$ alone, $5 \mu \mathrm{M}$ AZA with TSA $(300 \mathrm{nM})$, or the DMSO carrier and cultured for $48 \mathrm{~h}$, with media refreshed once during this time. This represented a $48 \mathrm{~h}$ preincubation \pm AZA (the action of AZA is passive and requires cell division for action). The treatment period commenced $72 \mathrm{~h}$ postdissection and consisted of the addition of $300 \mathrm{nM}$ TSA or DMSO carrier in fresh media, in the presence or absence of LPS $(5 \mu \mathrm{g} / \mathrm{mL})$, to the explants for a duration of $24 \mathrm{~h}$. The media were collected following the treatment and the wet weight of the tissue in each well determined so that cytokine production rates could be normalized. Measurements of pro- (IL1 $\beta$, TNF $\alpha$ ) and anti-inflammatory (IL10, IL1Ra) cytokines were conducted on cultured media using ELISAs according to manufacturers' specifications.

2.3. Statistical Analysis. Production rates of cytokines were calculated as picograms per gram wet tissue weight per $24 \mathrm{~h}$ and are presented as \% basal control values (means \pm SE, $n=$ $3)$. Statistical significance was determined by ANOVA, and $P<0.05$ was considered to be significant. 


\section{Results}

3.1. Effect of AZA and TSA on Cytokine Production by Villous Explants in the Presence or Absence of LPS. LPS treatment significantly $(P<0.05)$ increased the production of IL-1 $\beta$ ( 10-34-fold), TNF $\alpha$ ( 23->100-fold) and IL10 ( 6-10fold) after $24 \mathrm{~h}$ of treatment in villous explants, as expected. There were no significant LPS effects on IL1Ra production. AZA treatment did not have any significant effect on any cytokines' production tested either alone or in combination with LPS. Interestingly, however, the stimulatory effects of LPS on TNF $\alpha$ production were partially mitigated $(P<0.05)$ by TSA treatment in villous explants.

3.2. Effect of AZA and TSA on Cytokine Production by Amnion explants in the Presence or Absence of LPS. Neither LPS nor the TSA or AZA had any significant effect on the cytokine production in amnion explants after $24 \mathrm{~h}$ of treatment.

\section{Discussion}

Conceivably, epigenetic modifications (e.g., DNA methylation and covalent histone modifications) might render individuals more or less susceptible to either term or preterm birth by modulating the expression of genes that are effectors of the parturition pathway, for example, the contraction-associated proteins, COX-2, oxytocin, and prostaglandin receptors in myometrium [20]. Thus, some individuals may have a sensitive epigenetic phenotype that leads to an increased susceptibility to preterm labour. Global DNA methylation is increased in preterm preeclamptic placentae [21]. In this study, in conjunction with our previous work [18] we have shown that epigenetic regulation of cytokine production is tissue specific in gestational tissues. Caution of course should be exercised in the comparison of noncontemporaneous data. In choriodecidua AZA/TSA treatment resulted in a massive increase in IL- $1 \beta$ production in response to LPS whereas in amnion and villous placenta this did not occur although a small positive trend in mean production was noted (Figures 1 and 2). Our finding of TSA mitigation of LPS-stimulated TNF $\alpha$ production is most fascinating. This raises the question of TSA-like moieties being developed to attenuate inflammatory process in the human placenta. The disadvantage of such an approach is, of course, the enhancement of IL- $1 \beta$ production in choriodecidua by such an agent [18]. The tissue-specific nature of these regulatory mechanisms means that we must be cautious in our approach to such matters.

Amnion clearly does not respond to the inflammatory challenge of LPS although it remains a significant source of cytokine production and once activated can respond vigorously to modifications of the cytokine environment [22-25].

Villous placenta seems crudely to be more active in proinflammatory cytokine biosynthesis than anti-inflammatory cytokine biosynthesis. This is clearly dangerous for the fetus and may play a role in the fetal inflammatory syndrome [26], although clearly direct evidence must be obtained before conclusions are drawn.

\section{Conclusions}

Cytokine production in gestational tissues is regulated epigenetically in a tissue-specific manner. Furthermore, treatment with a histone deacetylation inhibitor can partially abrogate LPS-stimulated TNF $\alpha$ production in villous placenta but not amnion.

\section{References}

[1] J. Bryce, C. Boschi-Pinto, K. Shibuya, and R. E. Black, "WHO estimates of the causes of death in children," The Lancet, vol. 365, no. 9465, pp. 1147-1152, 2005.

[2] P. J. Laws and E. A. Sullivan, Australia's Mothers and Babies 2008, Perinatal statistics series no. 24. Cat. no. PER 50, Australian Institute of Health and Welfare (AIHW), Canberra, Australia, 2010.

[3] A. Bird, "DNA methylation patterns and epigenetic memory," Genes and Development, vol. 16, no. 1, pp. 6-21, 2002.

[4] A. P. Feinberg, R. A. Irizarry, D. Fradin et al., "Personalized epigenomic signatures that are stable over time and covary with body mass index," Science Translational Medicine, vol. 2, no. 49, Article ID 49ra67, 2010.

[5] M. W. Varner and M. S. Esplin, "Current understanding of genetic factors in preterm birth," International Journal of $\mathrm{Ob}$ stetrics and Gynaecology, vol. 112, no. 1, pp. 28-31, 2005.

[6] D. C. Dolinoy, D. Huang, and R. L. Jirtle, "Maternal nutrient supplementation counteracts bisphenol A-induced DNA hypomethylation in early development," Proceedings of the $\mathrm{Na}$ tional Academy of Sciences of the United States of America, vol. 104, no. 32, pp. 13056-13061, 2007.

[7] V. K. Rakyan, J. Preis, H. D. Morgan, and E. Whitelaw, "The marks, mechanisms and memory of epigenetic states in mammals," Biochemical Journal, vol. 356, no. 1, pp. 1-10, 2001.

[8] T. Kouzarides, "Chromatin modifications and their function," Cell, vol. 128, no. 4, pp. 693-705, 2007.

[9] M. F. Fraga, E. Ballestar, M. F. Paz et al., "Epigenetic differences arise during the lifetime of monozygotic twins," Proceedings of the National Academy of Sciences of the United States of America, vol. 102, no. 30, pp. 10604-10609, 2005.

[10] Y. Li, M. A. Reddy, F. Miao et al., "Role of the histone H3 lysine 4 methyltransferase, SET7/9, in the regulation of NF$\kappa \mathrm{B}$-dependent inflammatory genes: relevance to diabetes and inflammation," Journal of Biological Chemistry, vol. 283, no. 39, pp. 26771-26781, 2008.

[11] A. Gabory, L. Attig, and C. Junien, "Sexual dimorphism in environmental epigenetic programming," Molecular and Cellular Endocrinology, vol. 304, no. 1-2, pp. 8-18, 2009.

[12] C. Ling, P. Poulsen, S. Simonsson et al., "Genetic and epigenetic factors are associated with expression of respiratory chain component NDUFB6 in human skeletal muscle," Journal of Clinical Investigation, vol. 117, no. 11, pp. 3427-3435, 2007.

[13] C. Murgatroyd, Y. Wu, Y. Bockmühl, and D. Spengler, "Genes learn from stress: how infantile trauma programs us for depression," Epigenetics, vol. 5, no. 3, pp. 194-199, 2010.

[14] G. C. Burdge and K. A. Lillycrop, "Nutrition, epigenetics, and developmental plasticity: implications for understanding human disease," Annual Review of Nutrition, vol. 30, pp. 315$339,2010$.

[15] M. J. R. Heerwagen, M. R. Miller, L. A. Barbour, and J. E. Friedman, "Maternal obesity and fetal metabolic programming: a fertile epigenetic soil," American Journal of Physiology, vol. 299, no. 3, pp. R711-R722, 2010. 
[16] S. C. McQuown and M. A. Wood, "Epigenetic regulation in substance use disorders," Current Psychiatry Reports, vol. 12, no. 2, pp. 145-153, 2010.

[17] J. L. Fernandez-Morera, V. Calvanese, S. Rodriguez-Rodero, E. Menendez-Torre, and M. F. Fraga, "Epigenetic regulation of the immune system in health and disease," Tissue Antigens, vol. 76, no. 6, pp. 431-439, 2010.

[18] T. A. Sato and M. D. Mitchell, "Molecular inhibition of histone deacetylation results in major enhancement of the production of IL-1 $\beta$ in response to LPS," American Journal of Physiology, vol. 290, no. 3, pp. E490-E493, 2006.

[19] M. T. Coughlan, K. Oliva, H. M. Georgiou, J. M. H. Permezel, and G. E. Rice, "Glucose-induced release of tumour necrosis factor-alpha from human placental and adipose tissues in gestational diabetes mellitus," Diabetic Medicine, vol. 18, no. 11, pp. 921-927, 2001.

[20] M. D. Mitchell, "Unique suppression of prostaglandin H synthase-2 expression by inhibition of histone deacetylation, specifically in human amnion but not adjacent choriodecidua," Molecular Biology of the Cell, vol. 17, no. 1, pp. 549-553, 2006.

[21] A. Kulkarni, P. Chavan-Gautam, S. Mehendale, H. Yadav, and S. Joshi, "Global DNA methylation patterns in placenta and its association with maternal hypertension in Pre-eclampsia," DNA and Cell Biology, vol. 30, no. 2, pp. 79-84, 2011.

[22] K. L. Simpson, J. A. Keelan, and M. D. Mitchell, "Labourassociated changes in the regulation of production of immunomodulators in human amnion by glucocorticoids, bacterial lipopolysaccharide and pro-inflammatory cytokines," Journal of Reproduction and Fertility, vol. 116, no. 2, pp. 321-327, 1999.

[23] J. A. Keelan, K. W. Marvin, T. A. Sato, M. Coleman, L. M. E. McCowan, and M. D. Mitchell, "Cytokine abundance in placental tissues: evidence of inflammatory activation in gestational membranes with term and preterm parturition," American Journal of Obstetrics and Gynecology, vol. 181, no. 6, pp. 1530-1536, 1999.

[24] N. Laham, S. P. Brennecke, and G. E. Rice, "Interleukin-8 release from human gestational tissue explants: the effects of lipopolysaccharide and cytokines," Biology of Reproduction, vol. 57, no. 3, pp. 616-620, 1997.

[25] N. Laham, S. P. Brennecke, K. Bendtzen, and G. E. Rice, "Tumour necrosis factor $\alpha$ during human pregnancy and labour: maternal plasma and amniotic fluid concentrations and release from intrauterine tissues," European Journal of Endocrinology, vol. 131, no. 6, pp. 607-614, 1994.

[26] R. Romero, R. Gomez, F. Ghezzi et al., "A fetal systemic inflammatory response is followed by the spontaneous onset of preterm parturition," American Journal of Obstetrics and $G y$ necology, vol. 179, no. 1, pp. 186-193, 1998. 


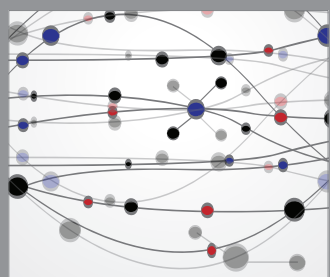

The Scientific World Journal
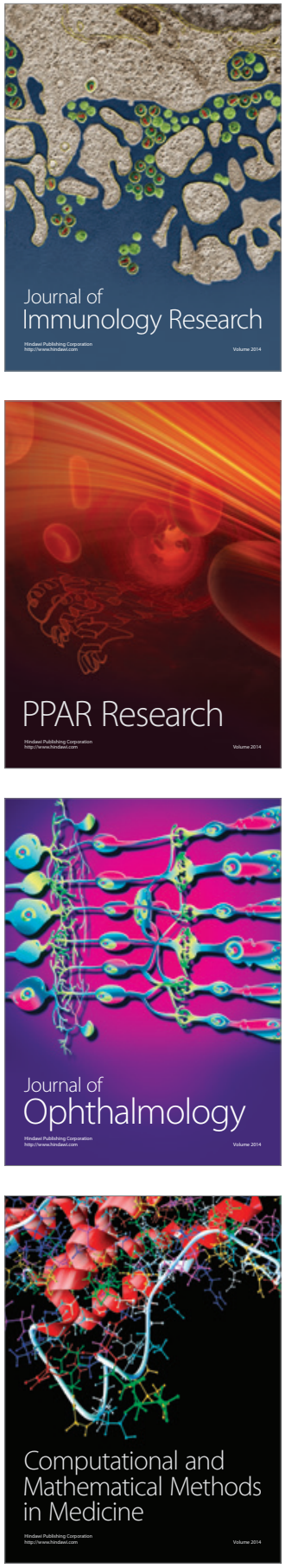

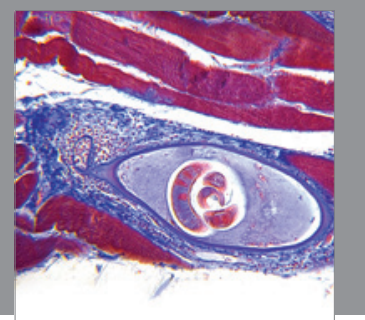

Gastroenterology

Research and Practice
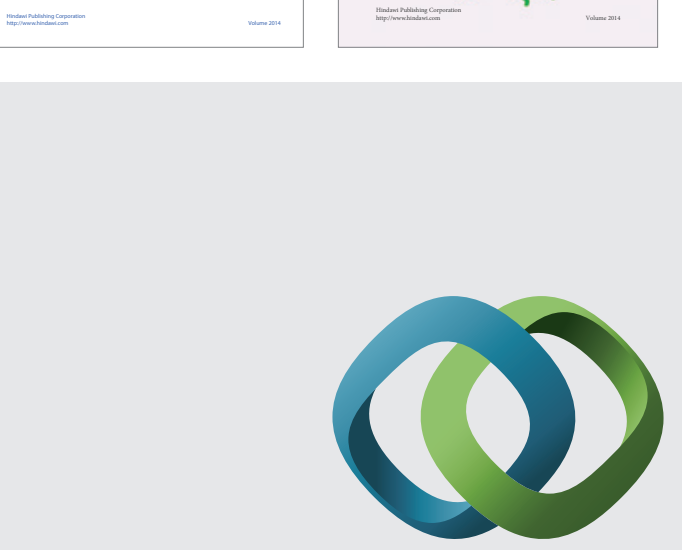

\section{Hindawi}

Submit your manuscripts at

http://www.hindawi.com
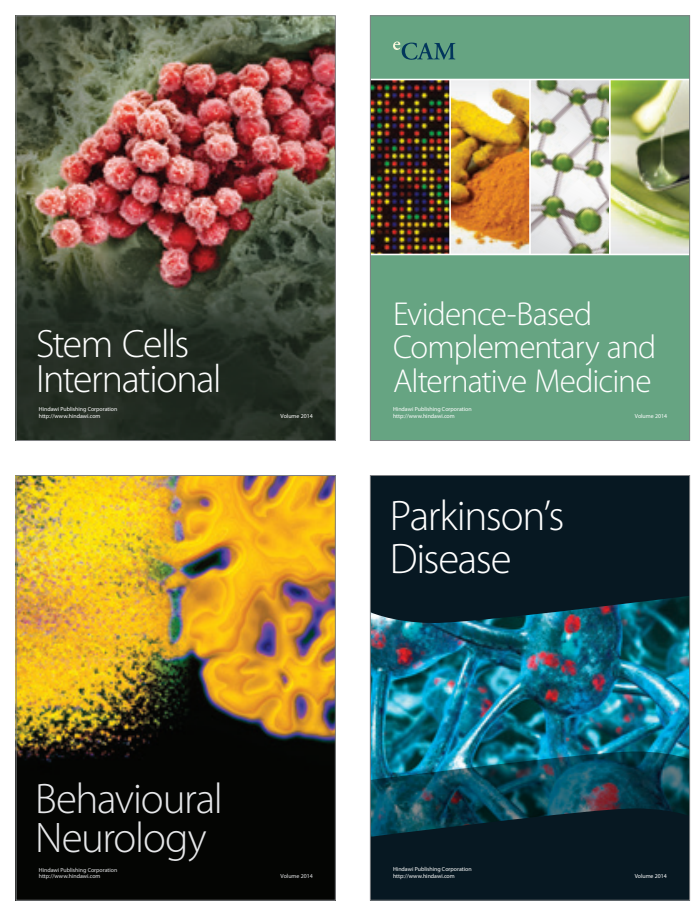

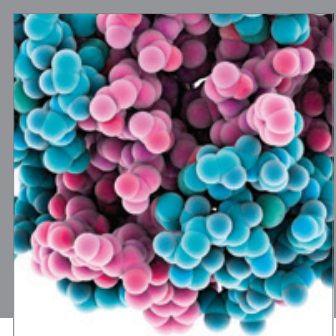

Journal of
Diabetes Research

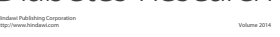

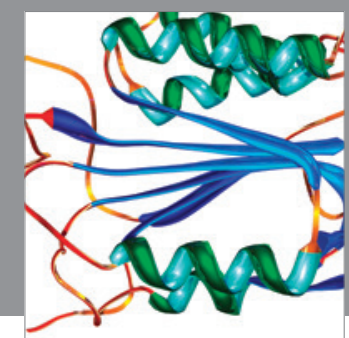

Disease Markers
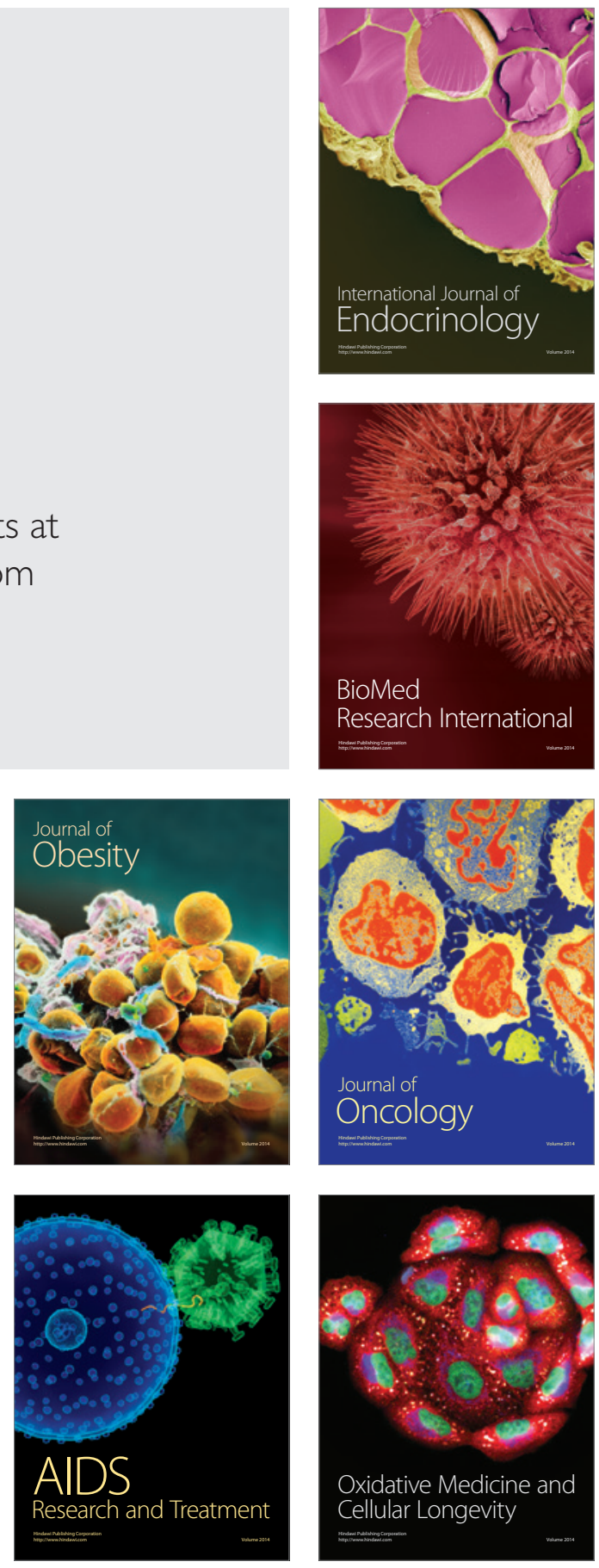